\title{
Visuomotor competencies and primary monosymptomatic nocturnal enuresis in prepubertal aged children
}

This article was published in the following Dove Press journal:

Neuropsychiatric Disease and Treatment

27 June 2013

Number of times this article has been viewed

\author{
Maria Esposito' \\ Beatrice Gallai \\ Lucia Parisi ${ }^{3}$ \\ Michele Roccella ${ }^{3}$ \\ Rosa Marotta ${ }^{4}$ \\ Serena Marianna Lavano ${ }^{4}$ \\ Giovanni Mazzotta ${ }^{5}$ \\ Giuseppina Patriciello' \\ Francesco Precenzano' \\ Marco Carotenuto' \\ 'Clinic of Child and Adolescent \\ Neuropsychiatry, Department of \\ Mental Health, Physical and Preventive \\ Medicine, Second University of \\ Naples, Italy; ${ }^{2}$ Unit of Child and \\ Adolescent Neuropsychiatry, \\ University of Perugia, Italy; ${ }^{3}$ Child \\ Neuropsychiatry, Department of \\ Psychology, University of Palermo, \\ Italy; ${ }^{4}$ Department of Psychiatry, \\ "Magna Graecia" University \\ of Catanzaro, Catanzaro, Italy; \\ ${ }^{5}$ Unit of Child and Adolescent \\ Neuropsychiatry, AUSL Umbria 2, \\ Terni, Italy
}

\begin{abstract}
Background: Primary monosymptomatic nocturnal enuresis (PMNE) is a common problem in the developmental ages; it is the involuntary loss of urine during the night in children older than 5 years of age. Several clinical observations have suggested an association between bedwetting and developmental delays in motricity, language development, learning disability, physical growth, and skeletal maturation. The aim of the present study is to evaluate the prevalence of fine motor coordination and visuomotor integration abnormalities in prepubertal children with PMNE.
\end{abstract}

Methods: The study population included 31 children (16 males, 15 females; mean age 8.14 years \pm 1.36 years), and the control group comprised 61 typical developing children (32 males, 29 females; mean age 8.03 years \pm 1.44 years). The whole population underwent a clinical evaluation to assess total intelligence quotient level, visuomotor integration (VMI) skills, and motor coordination performance (using the Movement Assessment Battery for Children, or M-ABC).

Results: No significant differences between the two study groups were found for age $(P=0.725)$, gender $(P=0.886)$, z-body mass index $(P=0.149)$, or intellectual abilities (total intelligence quotient) $(P=0.163)$. The PMNE group showed a higher prevalence of borderline performance on M-ABC evaluation and in pathologic performance on VMI Total Task compared to controls $(P<0.001)$. No significant differences between the two study groups were found for pathologic performances on the M-ABC $(P=0.07)$, VMI Visual Task $(P=0.793)$, and VMI Motor Task $(P=0.213)$.

Conclusion: Our findings pinpointed that PMNE should not be considered as a voiding disorder alone and, consequently, the children affected should be referred to specific rehabilitative programs that aim to improve motor coordination and visuomotor integration.

Keywords: primary monosymptomatic nocturnal enuresis, visuomotor integration, childhood rehabilitation, VMI, M-ABC

\section{Introduction}

Primary monosymptomatic nocturnal enuresis (PMNE) is a common problem in children during the developmental years with an estimated overall prevalence ranging from $1.6 \%$ to $15 \%$, and possible persistence during adolescence. ${ }^{1-4}$ PMNE is the involuntary loss of urine during the night in children older than 5 years of age, and is distinguished in primary and secondary forms. ${ }^{1-4}$

Moreover, nocturnal enuresis could be classified as monosymptomatic nocturnal enuresis, in which there are no daytime urinary symptoms, and nonmonosymptomatic nocturnal enuresis, which is accompanied by daytime urinary symptoms. ${ }^{5}$

The prevalence of nocturnal enuresis tends to decrease with age, supporting the traditional idea of maturational delay in voiding control, ${ }^{6,7}$ even if other mechanisms
Correspondence: Marco Carotenuto Clinic of Child and Adolescent Neuropsychiatry, Department of Mental Health, Physical and Preventive Medicine, Second University of Naples, Via Sergio Pansini 5 PAD XI, 80I3I Naples, Italy

Tel +39815666988

Fax +39 8I 5666694

Email marco.carotenuto@unina2.it 
may be involved. Viewing PMNE in this light could explain some of its accompanying symptoms and signs, such as sleep architecture alterations, ${ }^{7}$ academic disabilities, ${ }^{8}$ neuromotor delay, ${ }^{9}$ and minor neurologic dysfunction. ${ }^{10}$

On the other hand, the role of enuresis as a possible clinical marker of other pathologies seems to be confirmed by the growing number of studies of comorbid attentiondeficit hyperactivity disorder (ADHD) and bedwetting, ${ }^{11,12}$ suggesting that enuresis may be a marker of a peculiar clinical subtype of ADHD (such as the inattentive phenotype), as seen in genetic studies. ${ }^{13}$

On the other hand, enuretic children have a significantly higher incidence of fine and gross motor clumsiness, reduced spatial and visuomotor perception, speech and coordination defects, attention-deficit disorder, delayed developmental milestones, and certain sex-specific behavioral problems. ${ }^{14}$

To the best of our knowledge, there are no reports about the visuomotor integration ability in prepubertal subjects affected by PMNE.

Therefore, the aim of the present study is to evaluate the prevalence of fine motor coordination and visuomotor integration abnormalities using validated tools in a sample of children affected by PMNE to suggest a new rehabilitative perspective for this complex disorder.

\section{Materials and methods}

The study population included 31 subjects with PMNE (16 males; mean age 8.14 years, standard deviation $[\mathrm{SD}] \pm 1.36$ years) consecutively referred from primary care pediatricians for PMNE to the Clinic of Child and Adolescent Neuropsychiatry at the Second University of Naples. PMNE was diagnosed according to the International Children's Continence Society criteria. ${ }^{5}$

Exclusion criteria were neurologic (ie, epilepsy, headache) or psychiatric symptoms (ADHD, depression, behavioral problems), mental retardation (intelligence quotient $[\mathrm{IQ}] \leq 70$ ), borderline intellectual functioning (IQ of 71 to 84$),{ }^{15,16}$ obesity, and anticonvulsant or psychoactive drug administration.

The data obtained were compared to those from a control group of 61 typical developing children (32 males; mean age 8.03 years, $\mathrm{SD} \pm 1.44$ years; $P=0.725$ ) recruited in the Campania school region.

The subjects in both groups were recruited from the same urban area; all participants were Caucasian and were of middle-class socioeconomic status. All parents gave their written informed consent. The study was conducted according to the criteria of the Declaration of Helsinki. ${ }^{17}$
As previously reported, ${ }^{18}$ the whole population underwent a clinical evaluation to assess IQ level, visuomotor integration (VMI) skills, and the presence of developmental coordination disorder (DCD).

\section{Intellectual level assessment}

IQ was assessed by the Italian version of the Wechsler Intelligence Scale for Children third edition (WISC-III), ${ }^{19,20}$ applicable for children ranging from ages 6 years to 16 years. The WISC-III is comprised of 13 distinct subtests divided into two scales - a verbal scale and a performance scale. The six Verbal Scale tests use language-based items, whereas the seven performance scales use visuomotor items that are less dependent on language. Five of the subtests in each scale produce scale-specific IQ scores such as verbal IQ (VIQ) and performance IQ (PIQ), and the ten subtest scores produced a total scale IQ (Total-IQ). For this study, only the Total-IQ values were considered.

\section{Developmental test of VMI}

The fine motor coordination and the visuomotor integration was assessed with the Beery VMI task - a paper-andpencil test in which children have to imitate or copy up to 27 geometric forms with increasing complexity using paper and pencil. ${ }^{21}$ The test was stopped when a child made more than two errors in a row. Copying errors were marked if they reflected problems in fine motor coordination and a pure visuospatial problem. The Beery VMI task is specifically designed for children and takes about 10 minutes to complete. The Beery VMI scores were standardized for age and gender using normative data for the Italian general population. ${ }^{21}$

The percentile scores were used for diagnosing the visuomotor abnormalities in our sample. A value less than or equal to the 5 th percentile was considered to indicate VMI impairment.

\section{Movement Assessment Battery for Children (M-ABC)}

The impairment of motor coordination performance relative to age expectations was determined using the Movement Assessment Battery for Children (M-ABC). This test is frequently used in both clinical and research settings to assess children for DCD and has high reliability and validity. ${ }^{22}$ In fact, it assesses fine and gross motor skills using three manual dexterity tasks, two ball skills tasks, and three balance tasks, each of which is scored on a 5-point scale (Figure 1). The raw score of each item is then converted to a score on a scale ranging from 0 to 5 . A higher score 


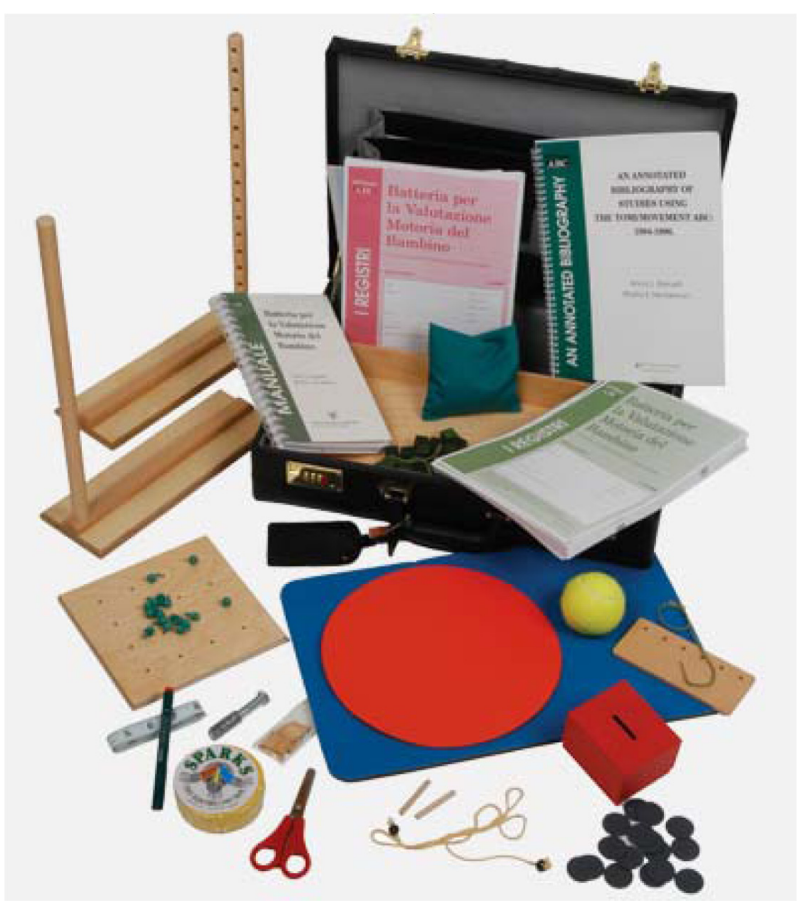

Figure I Materials of the Movement Assessment Battery for Children test.

indicates a less-than-adequate performance. Consequently, 0 reflects a complete success by the candidate on the task examined, while 5 reflects a failure in the execution of the task; a failed (F), an inappropriate (I), or a refused (R) performance is given a score of 5 . The sum of the eight scores of items corresponds to the total score of disability, ranging from $0-40$, where a higher score reflects a poor motor performance. The content of the items differs depending on the age of the child examined, with the assumption that increased difficulty is associated with age, so that the battery is made up of four different types of activities that were considered to be created in relation to age (4-6 years, 7-8 years, 9-10 years, and 11-12 years). Each subject was assessed individually in about $20-40$ minutes. $^{22}$

The total impairment score is calculated from these individual tasks and is used to generate a percentile score that is compared to the standard sample. Consistent with a recent meta-analysis, ${ }^{23}$ in this study, DCD was defined as a total score of less than or equal to the 5th percentile, and a cut-off score of less than or equal to the 15th percentile, was used to define borderline motor impairment.

\section{Statistical analysis}

Mean differences in anthropometric (z-score body mass index [z-BMI]) and clinical characteristics between the PMNE individuals and the control group were analyzed by $t$-test.
To evaluate the differences between both groups (PMNE and controls) in terms of the prevalence of the pathologic items of the VMI and M-ABC tests, the results were divided into "pathologic," "borderline," and "normal" scores using cut-off values in accordance with the validation criteria of the respective tests. Then, the Chi-square test was used to calculate the statistical difference. $P$-values $\leq 0.05$ were considered to be statistically significant.

The commercially available STATISTICA software (StatSoft, Inc, Tulsa, OK, USA) was used for the statistical evaluation.

\section{Results}

No significant differences between the two study groups were found for age $(P=0.725)$, gender $(P=0.886)$, z-BMI $(P=0.149)$, and intellectual abilities (Total IQ; $P=0.163$ ), as shown in Table 1.

The PMNE group had a higher prevalence of borderline performance ( $\leq 15$ th percentile) on the M-ABC evaluation (54.84\% of PMNE children; $P<0.001$ ) and of pathologic performance ( $\leq 5$ th percentile) on VMI total task $(38.71 \%$ of PMNE children) compared to controls $(P<0.001)$, as shown in Table 2.

No significant differences between the two study groups were found for pathologic performances ( $\leq 5$ th percentile) on the M-ABC $(P=0.07)$, the VMI visual task ( $\leq 5$ th percentile; $P=0.793)$, and the VMI motor task ( $\leq 5$ th percentile; $P=0.213)$ (see Table 2).

\section{Discussion}

Nocturnal bladder control may be considered as a key developmental milestone. ${ }^{24}$ In fact, a conscious sensation of bladder fullness generally tends to appear after the first year of life, allowing the development of voluntary control of voiding that begins around the age of 2 years. ${ }^{25} \mathrm{By}$ the age of 4 years, most children have acquired full daytime and nighttime urinary control. ${ }^{26,27}$

Table I Comparison of children affected by PMNE and typical developing subjects (normal)

\begin{tabular}{lccc}
\hline & $\begin{array}{l}\text { PMNE } \\
(\mathbf{n}=\mathbf{3} \mathbf{1})\end{array}$ & $\begin{array}{l}\text { Normal } \\
(\mathbf{n}=61)\end{array}$ & P-value \\
\hline Gender (M/F) & $16 / 15$ & $32 / 29$ & 0.886 \\
Age & $8.14 \pm 1.36$ & $8.03 \pm 1.44$ & 0.725 \\
z-BMI & $0.32 \pm 0.26$ & $0.41 \pm 0.29$ & 0.149 \\
Total IQ & $100.37 \pm 8.24$ & $102.86 \pm 7.93$ & 0.163 \\
\hline
\end{tabular}

Note: By gender, age, z-BMI, and total IQ. The t-test and Chi-square test, where appropriated, were applied. $P$-values $<0.05$ were considered statistically significant. Abbreviations: PMNE, primary monosymptomatic nocturnal enuresis; $n$, number; M, male; F, female; z-BMI, z-score body mass index; IQ, intelligence quotient. 
Table 2 Comparison of prevalence of pathologic or borderline performances between children affected by PMNE and normally developing children

\begin{tabular}{lllll}
\hline & $\begin{array}{l}\text { PMNE } \\
(\mathbf{n}=\mathbf{3 I})\end{array}$ & $\begin{array}{l}\text { Normal } \\
(\mathbf{n}=\mathbf{6 I})\end{array}$ & Chi-square & P-value \\
\hline M-ABC pathological & $4 / 27$ & $\mathrm{I} / 60$ & 3.119 & 0.07 \\
M-ABC borderline & $\mathrm{I} 7 / 14$ & $4 / 57$ & 24.528 & $<0.00 \mathrm{I}$ \\
VMI total score & $\mathrm{I} 2 / 19$ & $\mathrm{I} / 60$ & 20.324 & $<0.00 \mathrm{I}$ \\
VMI visual task & $\mathrm{I} / 30$ & $\mathrm{I} / 60$ & 0.069 & 0.793 \\
VMI motor task & $3 / 28$ & $\mathrm{I} / 60$ & $\mathrm{I} .553$ & $0.2 \mathrm{I3}$ \\
\hline
\end{tabular}

Notes: The Chi-square test was applied. P-values $<0.05$ were considered statistically significant.

Abbreviations: PMNE, primary monosymptomatic nocturnal enuresis; $n$, number; M-ABC, Movement Assessment Battery for Children; VMI, Visuomotor Integration.

In this respect, the idea that enuresis could be related to a sort of immaturity in the central nervous system seems to be supported by the higher prevalence of prematurity and/or low birth weight, ${ }^{28-31}$ and by the higher motor coordination impairment among enuretics compared to typical developing children. ${ }^{32}$

Alternatively, many typical comorbidities of PMNE, such as academic difficulties and ADHD-inattentive subtypes, ${ }^{8}$ could also be associated with motor coordination impairment. ${ }^{13}$ The relationship between the two conditions was also confirmed by our findings about the higher prevalence of a borderline performance in the $\mathrm{M}-\mathrm{ABC}$ test among PMNE subjects.

Several clinical observations have suggested an association between bedwetting and developmental delays in motricity, ${ }^{9,33}$ language development, ${ }^{34-38}$ learning disability, ${ }^{8}$ physical growth, ${ }^{35}$ and skeletal maturation. ${ }^{39,40}$ Moreover, the cooccurrence of PMNE and behavioral difficulties, especially hyperactive and inattentive behaviors, has been well documented. ${ }^{41-44}$

On the other hand, recent studies reported the presence of abnormal cerebello-thalamo-frontal functional connectivity in PMNE children, ${ }^{45,46}$ which could be considered to be related to attentional dysfunctions. In this respect, the findings about the impairment in VMI ability may be considered to be the effect of the altered cerebello-frontal connectivity. In fact, a report by Lei et al ${ }^{47,48}$ in 2012 showed an abnormal activation of the prefrontal cortex (PFC), which is involved in the planning complex that includes cognitive behaviors, decision making, and moderating proper social behavior, during both a Go/No-Go task and a resting state in children affected by PMNE. ${ }^{49}$

In our sample, the higher prevalence of pathologic performances in VMI ability in the absence of impairment in visual or motor tasks could be interpreted as a reduction in selective attention function, controlled by the PFC area and also connected to the periaqueductal grey matter, anterior cingulate cortex, insula, hypothalamus, and thalamus. ${ }^{47,48}$

In fact, all these brain areas are involved in the control of micturition and in other pathologies such as migraine without aura, ${ }^{50}$ which seems to have many mechanisms in common with PMNE. In fact, enuresis and migraine could be linked by the cortical system in terms of arousal dysfunction, vegetative hyperactivity, ${ }^{51-53}$ alteration in motor and visual coordination, ${ }^{18,27,54}$ and sleep disorders. ${ }^{55-57}$ As such, PMNE and migraine could be also exacerbated by family stress and/ or increase stress for the family. ${ }^{58,59}$

Thus, taken in this light, treatment of PMNE should not exclude the causal role of both sleep disorders and abnormal behavior, ${ }^{60}$ while also considering natural approaches such as sleep hygiene, ${ }^{61}$ nutraceuticals, ${ }^{62,63}$ and weight loss. ${ }^{64}$

Alternatively, our findings are derived from a descriptive cross-sectional study and were an attempt to show that PMNE should be not considered as a voiding disorder alone, because it is often accompanied by other underdiagnosed comorbidities. Consequently, for children with PMNE, it may be possible that specific rehabilitative programs that are oriented toward improving fine motor coordination and VMI skills may be beneficial.

Herein, we should take into account a limitation of this study: our data were derived from a small sample of children affected by PMNE. Notwithstanding this limitation, our study may suggest a new perspective in the management and rehabilitation of pediatric PMNE. Focusing on the relationship between visuomotor impairment and PMNE could represent a not-yet-understood or identified comorbidity; thus, further studies may be warranted.

\section{Disclosure}

The authors report no conflicts of interest in this work. None of the authors has any personal or financial support or involvement with any organization with financial interests in the subject matter, or that holds any actual or potential conflict of interest.

\section{References}

1. Sakellaropoulou AV, Hatzistilianou MN, Emporiadou MN, et al. Association between primary nocturnal enuresis and habitual snoring in children with obstructive sleep apnoea-hypopnoea syndrome. Arch Med Sci. 2012;8(3):521-527.

2. Butler RJ, Golding J, Heron J; for ALSPAC Study Team. Nocturnal enuresis: a survey of parental coping strategies at $71 / 2$ years. Child Care Health Dev. 2005;31(6):659-667.

3. Caldwell PH, Edgar D, Hodson E, Craig JC. 4. Bedwetting and toileting problems in children. Med J Aust. 2005;182(4):190-195. 
4. Chiozza ML, Bernardinelli L, Caione P, et al. An Italian epidemiological multicentre study of nocturnal enuresis. Br J Urol. 1998;81 Suppl 3: 86-89.

5. Nevéus T, von Gontard A, Hoebeke P, et al. The standardization of terminology of lower urinary tract function in children and adolescents: report from the Standardisation Committee of the International Children's Continence Society. J Urol. 2006;176(1):314-324.

6. Mac Keith RC. Is maturation delay a frequent factor in the origins of primary nocturnal enuresis? Dev Med Child Neurol. 1972;14(2): 217-223.

7. Esposito M, Gallai B, Parisi L, et al. Primary nocturnal enuresis as a risk factor for sleep disorders: an observational questionnaire-based multicenter study. Neuropsychiatr Dis Treat. 2013;9:437-443.

8. Esposito M, Carotenuto M, Roccella M. Primary nocturnal enuresis and learning disability. Minerva Pediatr. 2011;63(2):99-104.

9. Von Gontard A, Schmelzer D, Seifen S, Pukrop R. Central nervous system involvement in nocturnal enuresis: evidence of general neuromotor delay and specific brainstem dysfunction. J Urol. 2001;166(6) 2448-2451.

10. Lunsing RJ, Hadders-Algra M, Touwen BC, Huisjes HJ. Nocturnal enuresis and minor neurological dysfunction at 12 years: a follow-up study. Dev Med Child Neurol. 1991;33(5):439-445.

11. Shreeram S, He JP, Kalaydjian A, Brothers S, Merikangas KR. Prevalence of enuresis and its association with attention-deficit/ hyperactivity disorder among US. children: results from a nationally representative study. J Am Acad Child Adolesc Psychiatry. 2009;48(1): $35-41$.

12. Baeyens D, Roeyers H, Van Erdeghem S, Hoebeke P, Vande Walle J. The prevalence of attention deficit-hyperactivity disorder in children with nonmonosymptomatic nocturnal enuresis: a 4-year followup study. J Urol. 2007;178(6):2616-2620.

13. Elia J, Takeda T, Deberardinis R, et al. Nocturnal enuresis: a suggestive endophenotype marker for a subgroup of inattentive attention-deficit/ hyperactivity disorder. J Pediatr. 2009;155(2):239-244. e5.

14. Sarici SU, Kismet E, Türkbay T, et al. Bone mineral density in children with nocturnal enuresis. Int Urol Nephrol. 2003;35(3):381-385.

15. Esposito M, Carotenuto M. Intellectual disabilities and power spectra analysis during sleep: a new perspective on borderline intellectual functioning. J Intellect Disabil Res. Epub March 21, 2013.

16. Esposito M, Carotenuto M. Borderline intellectual functioning and sleep: the role of cyclic alternating pattern. Neurosci Lett. 2010;485(2): 89-93.

17. World Medical Association. World Medical Association Declaration of Helsinki: ethical principles for medical research involving human subjects [webpage on the Internet]. Geneva, Switzerland: World Health Organization; 2008. Available from: http://www.wma.net/ en/30publications/10policies/b3/. Accessed February 16, 2013.

18. Esposito M, Verrotti A, Gimigliano F, et al. Motor coordination impairment and migraine in children: a new comorbidity? Eur J Pediatr. 2012;171(11):1599-1604.

19. Orsini A, Picone L. WISC-III. Contributo alla taratura Italiana [webpage on the Internet]. Firenze, Italy: Giunti OS Organizzazioni Speciali; 2006. Available from: http://www.giuntios.it/it/catalogo/VO35. Accessed May 30, 2013. Italian.

20. Wechsler D. Wechsler Intelligence Scale for Children, 3rd ed. San Antonio, TX: The Psychological Corporation; 1991.

21. Beery KE, Beery NA. Beery-Buktenica Developmental Test of Visual-Motor Integration, 5th ed. Minneapolis, MN: NCS Pearson Inc; 2004.

22. Henderson SE, Sugden DA. Movement Assessment Battery for Children. London, UK: The Psychological Corporation; 1992.

23. Williams J, Lee KJ, Anderson PJ. Prevalence of motor-skill impairment in preterm children who do not develop cerebral palsy: a systematic review. Dev Med Child Neurol. 2009;52(3):232-237.

24. Kolvin I, MacKeith RC, Meadows SR, editors. Bladder Control and Enuresis. London, UK: Spastics International Medical Publications; 1973.
25. Berk LB, Friman PC. Epidemiologic aspects of toilet training. Clin Pediatr (Phila). 1990;29(5):278-282.

26. Bakker E, van Gool J, Wyndaele JJ. Results of a questionnaire evaluating different aspects of personal and familial situation, and the methods of potty-training in two groups of children with a different outcome of bladder control. Scand J Urol Nephrol. 2001;35(5):370-376.

27. Touchette E, Petit D, Paquet J, Tremblay RE, Boivin M, Montplaisir JY. Bed-wetting and its association with developmental milestones in early childhood. Arch Pediatr Adolesc Med. 2005;159(12):1129-1134.

28. Oppel WC, Harper PA, Rider RV. The age of attaining bladder control. Pediatrics. 1968;42(4):614-626.

29. Drillien CM. A longitudinal study of the growth and development of prematurely and maturely born children. Part V. Patterns of maternal care (a study of child rearing in Scotland). Arch Dis Child. 1959;34: 487-494.

30. Järvelin MR, Vikeväinen-Tervonen L, Moilanen I, Huttunen NP. Enuresis in seven-year-old children. Acta Paediatr Scand. 1988;77(1): $148-153$.

31. Liu X, Sun Z, Neiderhiser JM, Uchiyama M, Okawa M. Low birth weight, developmental milestones, and behavioral problems in Chinese children and adolescents. Psychiatry Res. 2001;101(2):115-129.

32. Davis NM, Ford GW, Anderson PJ, Doyle LW; for Victorian Infant Collaborative Study Group. Developmental coordination disorder at 8 years of age in a regional cohort of extremely-low-birthweight or very preterm infants. Dev Med Child Neurol. 2007;49(5):325-330.

33. Ornitz EM, Russell AT, Hanna GL, et al. Prepulse inhibition of startle and the neurobiology of primary nocturnal enuresis. Biol Psychiatry. 1999;45(11):1455-1466.

34. Fergusson DM, Horwood LJ, Shannon FT. Factors related to the age of attainment of nocturnal bladder control: an 8-year longitudinal study. Pediatrics. 1986;78(5):884-890.

35. Barbour RF, Borland EM, Boyd MM, Miller A, Oppe TE. Enuresis as a disorder of development. Br Med J. 1963;2(5360):787-790.

36. Essen J, Peckham C. Nocturnal enuresis in childhood. Dev Med Child Neurol. 1976;18(5):577-589.

37. Järvelin MR. Developmental history and neurological findings in enuretic children. Dev Med Child Neurol. 1989;31(6):728-736.

38. Kawauchi A, Tanaka Y, Yamao Y, et al. Follow-up study of bedwetting from 3 to 5 years of age. Urology. 2001;58(5):772-776.

39. Mimouni M, Shuper A, Mimouni F, Grünebaum M, Varsano I. Retarded skeletal maturation in children with primary enuresis. Eur J Pediatr. 1985;144(3):234-235.

40. Dündaröz MR, Sarici SU, Denli M, Aydin HI, Kocaoğlu M, Ozişik T Bone age in children with nocturnal enuresis. Int Urol Nephrol. 2001; 32(3):389-391.

41. Byrd RS, Weitzman M, Lanphear NE, Auinger P. Bed-wetting in US children: epidemiology and related behavior problems. Pediatrics. 1996; 98(3 Pt 1):414-419.

42. Robson WL, Jackson HP, Blackhurst D, Leung AK. Enuresis in children with attention-deficit hyperactivity disorder. South Med J. 1997;90(5): 503-505.

43. Bailey JN, Ornitz EM, Gehricke JG, Gabikian P, Russell AT, Smalley SL. Transmission of primary nocturnal enuresis and attention deficit hyperactivity disorder. Acta Paediatr. 1999;88(12):1364-1368.

44. Chang SS, Ng CF, Wong SN; for Hong Kong Childhood Enuresis Study Group. Behavioural problems in children and parenting stress associated with primary nocturnal enuresis in Hong Kong. Acta Paediatr. 2002;91(4):475-479.

45. Yu B, Sun H, Ma H, et al. Aberrant whole-brain functional connectivity and intelligence structure in children with primary nocturnal enuresis. PLoS One. 2013;8(1):e51924.

46. Yu B, Kong F, Peng M, Ma H, Liu N, Guo Q. Assessment of memory/ attention impairment in children with primary nocturnal enuresis: a voxelbased morphometry study. Eur J Radiol. 2012;81(12):4119-4122.

47. Lei D, Ma J, Shen X, et al. Changes in the brain microstructure of children with primary monosymptomatic nocturnal enuresis: a diffusion tensor imaging study. PLoS One. 2012;7(2):e31023. 
48. Lei D, Ma J, Du X, Shen G, Tian M, Li G. Altered brain activation during response inhibition in children with primary nocturnal enuresis: an fMRI study. Hum Brain Mapp. 2012;33(12):2913-2919.

49. Mukherjee P, Miller JH, Shimony JS, et al. Normal brain maturation during childhood: developmental trends characterized with diffusiontensor MR imaging. Radiology. 2001;221(2):349-358.

50. Carotenuto M, Esposito M, Pascotto A. Migraine and enuresis in children: An unusual correlation? Med Hypotheses. 2010;75(1):120-122.

51. Yakinci C, Müngen B, Durmaz Y, Balbay D, Karabiber H. Autonomic nervous system functions in children with nocturnal enuresis. Brain Dev. 1997;19(7):485-487.

52. Dundaröz MR, Denli M, Uzun M, et al. Analysis of heart rate variability in children with primary nocturnal enuresis. Int Urol Nephrol. 2001; 32(3):393-397.

53. Yerdelen D, Acil T, Goksel B, Karatas M. Heart rate recovery in migraine and tension-type headache. Headache. 2008;48(2):221-225.

54. Bosson S, Holland PC, Barrow S. A visual motor psychological test as a predictor to treatment in nocturnal enuresis. Arch Dis Child. 2002; 87(3):188-191.

55. Carotenuto M, Guidetti V, Ruju F, Galli F, Tagliente FR, Pascotto A. Headache disorders as risk factors for sleep disturbances in school aged children. J Headache Pain. 2005;6(4):268-270.

56. Vendrame M, Kaleyias J, Valencia I, Legido A, Kothare SV. Polysomnographic findings in children with headaches. Pediatr Neurol. 2008;39(1):6-11.
57. Bruni O, Miano S, Galli F, Verrillo E, Guidetti V. Sleep apnea in childhood migraine. J Headache Pain. 2000;1(3):169-172.

58. De Bruyne E, Van Hoecke E, Van Gompel K, et al. Problem behavior, parental stress and enuresis. J Urol. 2009;182(Suppl 4):2015-2020.

59. Esposito M, Gallai B, Parisi L, et al. Maternal stress and childhood migraine: a new perspective on management. Neuropsychiatr Dis Treat. 2013;9:351-355.

60. Carotenuto M, Esposito M, Precenzano F, Castaldo L, Roccella M. Cosleeping in childhood migraine. Minerva Pediatr. 2011;63(2): 105-109.

61. Carotenuto M, Gallai B, Parisi L, Roccella M, Esposito M. Acupressure therapy for insomnia in adolescents: a polysomnographic study. Neuropsychiatr Dis Treat. 2013;9:157-162.

62. Esposito M, Ruberto M, Pascotto A, Carotenuto M. Nutraceutical preparations in childhood migraine prophylaxis: effects on headache outcomes including disability and behaviour. Neurol Sci. 2012;33(6): $1365-1368$

63. Esposito M, Carotenuto M. Ginkgolide B complex efficacy for brief prophylaxis of migraine in school-aged children: an open-label study. Neurol Sci. 2011;32(1):79-81.

64. Verrotti A, Agostinelli S, D'Egidio C, et al. Impact of a weight loss program on migraine in obese adolescents. Eur J Neurol. 2013;20(2): 394-397.
Neuropsychiatric Disease and Treatment

\section{Publish your work in this journal}

Neuropsychiatric Disease and Treatment is an international, peerreviewed journal of clinical therapeutics and pharmacology focusing on concise rapid reporting of clinical or pre-clinical studies on a range of neuropsychiatric and neurological disorders. This journal is indexed on PubMed Central, the 'PsycINFO' database and CAS.

\section{Dovepress}

The manuscript management system is completely online and includes a very quick and fair peer-review system, which is all easy to use. Visit http://www.dovepress.com/testimonials.php to read real quotes from published authors. 